\title{
Power change in amorphous silicon technology by low temperature annealing
}

\author{
Ankit Mittal ${ }^{1,2, a}$, Marcus Rennhofer ${ }^{1}$, Angelika Dangel ${ }^{1}$, Bogdan Duman ${ }^{1}$, and Victor Schlosser ${ }^{2}$ \\ 1 Photovoltaics System, Austrian Institute of Technology, 1220 Vienna, Austria \\ 2 Department of Physics, University of Vienna, 1010 Vienna, Austria
}

Received: 1st October 2014 / Received in final form: 6 March 2015 / Accepted: 16 June 2015

Published online: 10 July 2015

(C) A. Mittal et al., published by EDP Sciences, 2015

\begin{abstract}
Amorphous silicon (a-Si) is one of the best established thin-film solar-cell technologies. Despite its long history of research, it still has many critical issues because of its defect rich material and its susceptibility to degrade under light also called as Staebler-Wronski effect (SWE). This leads to an increase in the defect density of a-Si, but as a metastable effect it can be completely healed at temperatures above $170{ }^{\circ} \mathrm{C}$. Our study is focused on investigating the behavior of annealing of different a-Si modules under low temperature conditions below $80{ }^{\circ} \mathrm{C}$ indicated by successive change of module power. These conditions reflect the environmental temperature impact of the modules in the field, or integrated in buildings as well. The power changes were followed by STC power rating and investigation of modulepower evolution under low irradiance conditions at $50 \mathrm{~W} / \mathrm{m}^{2}$. Our samples were recovered close to their initial state of power, reaching as high as $99 \%$ from its degraded value. This shows the influence of low temperature annealing and light on metastable module behavior in a-Si thin-film modules.
\end{abstract}

\section{Introduction}

The demand of amorphous silicon in the photovoltaic industry was growing quite rapidly for several years, which gave this technology a substantial share in the market [1]. Marginal cost of amorphous silicon (a-Si) is playing its decent role in the green energy market, since in many parts of the world has the short fall in energy supply [2]. Further research to make the a-Si technology cheaper with higher efficiency is therefore needed. Under diffuse light conditions, this technology is found to be good and can yield better performance than crystalline silicon $[3,4]$. Therefore, it is an optimal technology for applications in the tropical climates, low AM, high turbidity and tends to give better performance behavior in blue light than in the red spectrum of the sun [4-9].

It is also a suitable technology for installing the modules in facades as it has low temperature coefficients for power and power gain due to thermal annealing effect during its operation outdoors [3].

The SWE has been known for many decades. It leads to a reduction in photoconductivity and dark conductivity of the a-Si solar cells [10]. Although the effect has been

${ }^{a}$ e-mail: ankit.mittal.fl@ait.ac.at studied for many decades a commonly agreed reason for the cause of this effect is still unknown. Therefore, degradation effects are central focus for understanding the fully behavior and formation of this PV material. A-Si technology has a unique property which leads in reversibility of the degraded photoconductivity, which is unique under all PV technologies. It can be attained by heating the cell at $170{ }^{\circ} \mathrm{C}[11]$ which leads to annihilation of all the defects.

Many defect models have been proposed to explain this phenomenon. The Bond breaking model was the first widely accepted model to explain this phenomenon in terms of electronic properties [12]. Thereafter, the Hydrogen collision model came [13] and then cluster phase model [14].

In this paper, all the experiments were carried out at the commercial module level in order to analyze the impact of low temperature annealing and low light irradiance on the modules maximum power. This was chosen in order to reflect out-door conditions. The experimental section will explain about the procedures followed during the low temperature annealing of the modules. The results and discussion section will show the recovery of the a-Si modules initial power at low temperature annealing and further discuss the influence of metastabilities due to pretreatment effect under light and in dark. 
Table 1. Modules used during the experiment.

\begin{tabular}{cccc}
\hline Modules & $\begin{array}{c}\text { Annealing } \\
\text { temp. }\left[{ }^{\circ} \mathrm{C}\right]\end{array}$ & $\begin{array}{c}\text { Initial } \\
\text { power }[\mathrm{Wp}]\end{array}$ & Stabilization \\
\hline sample 1 & $60-70$ & 116 & outdoor \\
sample 2 & $65-70$ & 118 & indoor \\
sample 3 & $60-70$ & 2 & indoor \\
\hline
\end{tabular}
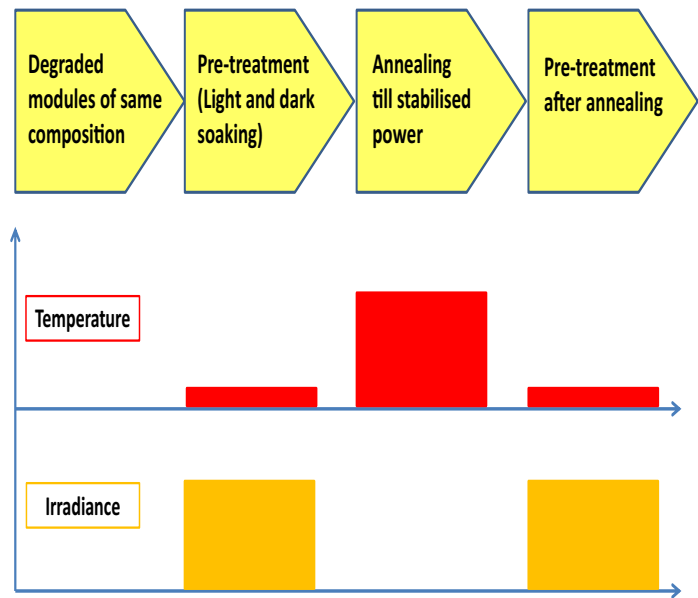

Fig. 1. Experimental scheme to analyze the effect of temperature and irradiance on a-Si modules.

\section{Experimental details}

Various commercial modules of double junction a-Si, stabilized indoors and outdoors were used for the experiments. The chosen a- Si modules are tabulated in Table 1 . The samples 1 and 2 were the commercial modules $(1.1 \mathrm{~m} \times 1.3 \mathrm{~m})$ of double junction a-Si on a glass substrate. The sample 3 was a-Si double junction on a polymer substrate type with a size of $15 \mathrm{~cm} \times 45 \mathrm{~cm}$.

Sample 1 was held outdoors operating at close to short circuit current (exactly at $V=1 / 3 \times V_{O C}$, STC) for around 3 years. Samples 2 and 3 were stabilized indoors using a BAA-class static sun simulator.

\subsection{Measurement protocol}

The basic measurement protocol to see the effect of annealing and low irradiance is shown in Figure 1. Following scheme was:

a. degradation of the modules;

b. pre-treatment cycle, as described in Section 2.4;

c. annealing at low temperature, as described in Section 2.2;

d. pre-treatment.

After step (a), steps (b)-(d) were repeated until the module power was stabilized.

\subsection{Low temperature annealing}

All the chosen modules were put in a climatic chamber at a particular temperature for a certain time until the power got stabilized at that temperature i.e. when the power from the two two successive annealing steps were almost equivalent to each other. Low temperature annealing of the modules were initiated at $60{ }^{\circ} \mathrm{C}$ (except for sample 2), $65{ }^{\circ} \mathrm{C}$ and $70{ }^{\circ} \mathrm{C}$. All modules were annealed completely in dark. Sample 2 was annealed in light and dark both. This was done by annealing it at a temperature $T_{i}$ under illumination until stabilization, which means less than $\pm 1 \%$ change in power from the last measurement point, and then the measurement protocol was followed (see Sect. 2.1, (b)-(d) again at $T_{i}$ ).

\subsection{Power rating}

During the annealing period a successive IV characterization was done after $30 \mathrm{~h}$ to $65 \mathrm{~h}$ of annealing in a pulsed solar simulator for each module, respectively. All measurements were done according to the IEC 60904 standard (procedure for IV characteristics measurement) [15] and corrected according to the IEC 60891 for the temperature and irradiance correction [16] at STC (Standard test conditions i.e. $1000 \mathrm{~W} / \mathrm{m}^{2}, 25^{\circ} \mathrm{C}$, Air mass 1.5) [17].

\subsection{Illumination under low-light conditions}

To measure the effect of the annealing on the power rating in more detail prior to the STC power rating as described in Section 2.3, a pre-treatment was carried out. Before the start of pre-treatment, the modules were stored in dark overnight to eliminate any effects from light. In pre-treatment, the modules were illuminated ("light soaking" - LS) for $2 \mathrm{~h}$ and then immediately stored in dark ("dark soaking" - DS) for $2 \mathrm{~h}$. The modules were exposed to an irradiance of $\sim 50 \mathrm{~W} / \mathrm{m}^{2}$ during $\mathrm{LS}$, and for successive time intervals an IV-curve was measured in a pulsed solar simulator at STC conditions for both LS and DS cycle. The detailed procedure for the thin film pretreatment as done here is described elsewhere [18-20]. A pre-treatment cycle was performed to show that annealed modules have a much stable behavior regarding power changes from low light illumination as they appear at lab manipulation and handling (approx. $50 \mathrm{~W} / \mathrm{m}^{2}$ ).

\subsection{Arrhenius' law}

The Arrhenius equation is a simple and accurate formula for the temperature dependence of the reaction rate constant. It is valid, if the basic activated mechanism is following the thermal Boltzmann statistics of energy distribution. Here it is used as an indicator for thermal activation of the changes in the modules resulting from the annealing procedure.

An approach to the evaluation here was a standard Arrhenius behavior in which the relationship between defects and other intrinsic parameters and the power change with the temperature. Here the temperature $T$ dependent parameter tested was the modules power $P$ - $(T)$, while the 


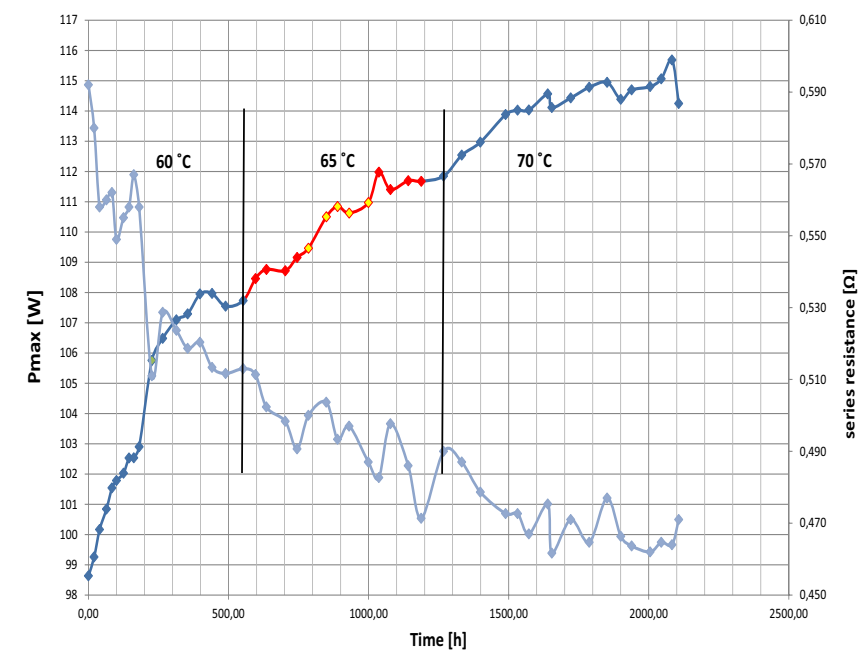

Fig. 2. Power evolution vs. series resistance of sample 1, annealed in dark. The lines are for guidance to the eyes.

intrinsic constants $c_{0}$ and $c_{1}$ linking the materials properties changing in the modules cells and the power are still unknown and will be measure of experiments to follow.

$$
c_{0} \Delta P(T)=c_{1} \Delta P_{0} e^{\frac{-E_{a}}{k T}},
$$

where $E_{a}$ is the activation energy of the driving process in $[\mathrm{J}], k$ is the Boltzmann constant and $T$ is the temperature in $[K]$.

\section{Results and discussion}

\subsection{Experimental results}

\subsubsection{Impact on module power}

All modules annealed showed an increase in their STC power. The increase depends on the history of the module and the annealing temperature. The power of sample 1 (cf. Tab. 1), which was prior degraded outdoor, increased $16.5 \%$ from its degraded state as shown in Figure 2 along with its series resistance. In Table 2, the relative and absolute increase in power from annealing is also shown.

Series resistance is generally caused by the intrinsic resistance of the a-Si cell and all successive transition resistances (e.g. between metal contact and silicon). Its increase causes loss in performance of the module. In sample 1 a decrease of the series resistance from $0.51 \Omega$ to $0.46 \Omega$ was registered, as shown in Figure 2. Also, the shunt resistance is caused by the manufacturing defects. Low shunt resistance in a solar cell, cause loss in power by providing an alternate current path. Here, the shunt resistance was increased from $42.8 \Omega$ to $64.3 \Omega$ along with power, as shown in Figure 3.

The changes in series and shunt resistances are small, but they are shown in graphs correlating to the power change with each annealing cycle.

In Figure 2, the first part for about $550 \mathrm{~h}$ represent the $60{ }^{\circ} \mathrm{C}$ annealing. The module has stabilized after
Table 2. Power evolution for sample 1.

\begin{tabular}{ccccc}
\hline $\begin{array}{c}\text { Temp. } \\
{\left[{ }^{\circ} \mathrm{C}\right]}\end{array}$ & $\begin{array}{c}\text { Power } \\
{[\mathrm{W}]}\end{array}$ & $\begin{array}{c}\text { Power } \\
{[\%]}\end{array}$ & \multicolumn{2}{c}{$116 \mathrm{Wp}=100 \%$} \\
\hline 25 & 98.6 & 100 & 85 & \\
60 & 107.7 & 109.2 & 92.9 & +7.9 \\
65 & 111.7 & 113.2 & 96.3 & +3.4 \\
70 & 114.9 & 116.5 & 99.0 & +2.7 \\
\hline
\end{tabular}

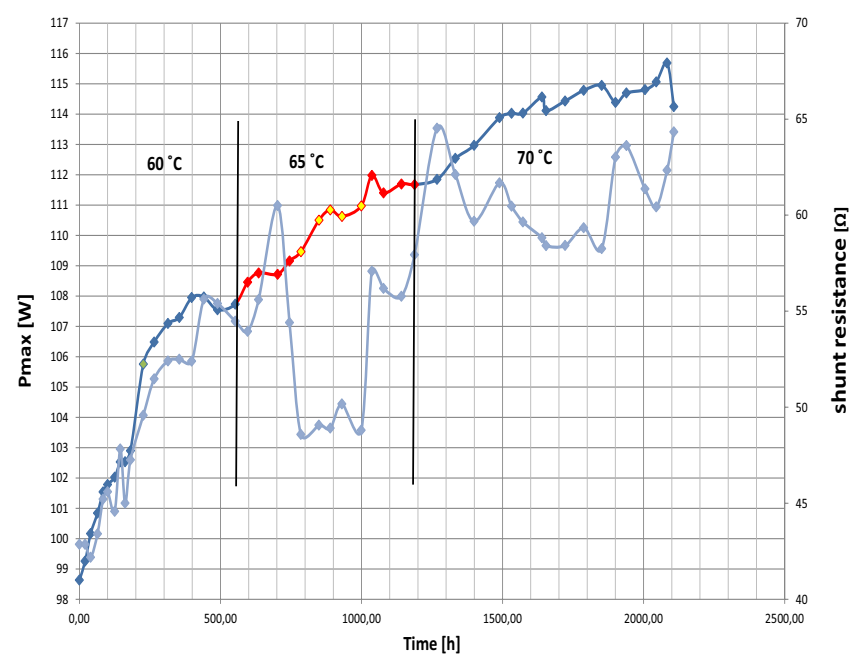

Fig. 3. Power evolution vs. shunt resistance of sample 1, annealed in dark. The lines are for guidance to the eyes.

about 553 h starting at $98.6( \pm 0.2 \%)$ Watt peak $(\mathrm{Wp})$ and a final stabilized value of $107.7 \mathrm{Wp}( \pm 0.2 \%)$ of power. This results in a performance improvement of $9.1 \mathrm{~W}(9.2 \%)$. At $65{ }^{\circ} \mathrm{C}$ cycle, the stabilized final value was reached after $635 \mathrm{~h}$ with $111.7 \mathrm{Wp}( \pm 0.2 \%)$, resulting in a further increase of $4 \mathrm{~W}(4 \%)$. At $70{ }^{\circ} \mathrm{C}$ the module finally reached $114.9 \mathrm{Wp}( \pm 0.2 \%)$ after $920 \mathrm{~h}$. The power increase from $65{ }^{\circ} \mathrm{C}$ to $70{ }^{\circ} \mathrm{C}$ cycle was $3.2 \mathrm{~W}(3.3 \%)$. Thus, the overall increase for three runs is $16.3 \mathrm{Wp}$, i.e. $16.5 \%$ from the degraded value.

In Figure 4, the relative increase in power of the module for each temperature step is shown. All temperature steps lead to an increase of power. The initial power value after manufacturing (data sheet value of $116 \mathrm{Wp}$ ) was not reached.

A different behavior was found for the flexible thin film module, sample 3 as given in Figure 5 . The performance at the first measuring point was $1.82 \mathrm{Wp}$ (stabilized value). After about $553 \mathrm{~h}$ at $60^{\circ} \mathrm{C}$ the power increased to $1.93 \mathrm{Wp}$ $( \pm 0.8 \%)$. This results in an increase of $0.11 \mathrm{Wp}(6.2 \%)$. During the $65{ }^{\circ} \mathrm{C}$ and $70{ }^{\circ} \mathrm{C}$ run, no further change in power was registered.

In Table 3 the maximum power change due to annealing is summarized.

\subsubsection{Impact on low light behavior}

Before starting with annealing, a pre-treatment cycle was performed, as explained in Section 2.4. After 


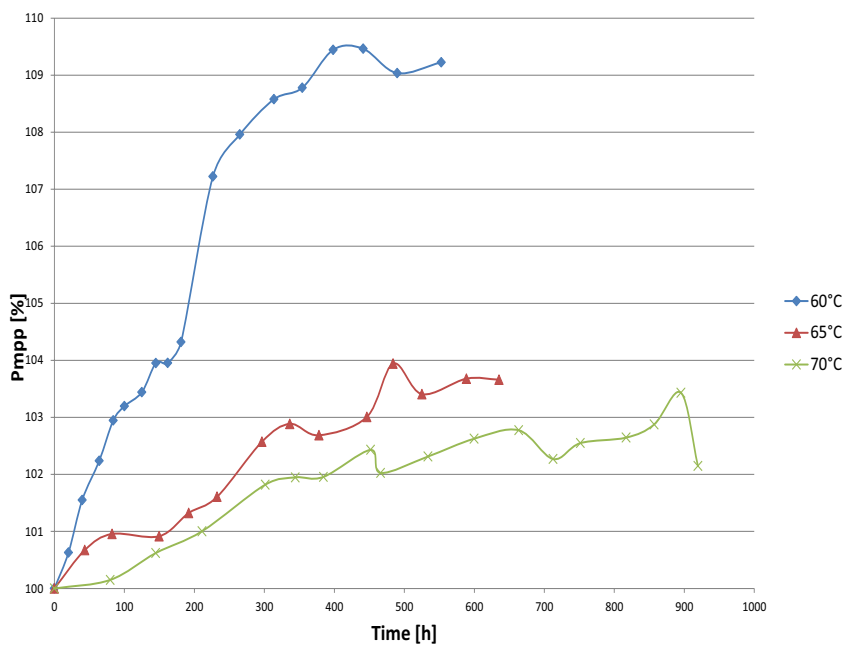

Fig. 4. Power curve normalized to its initial state at each annealing temperature of sample 1 .

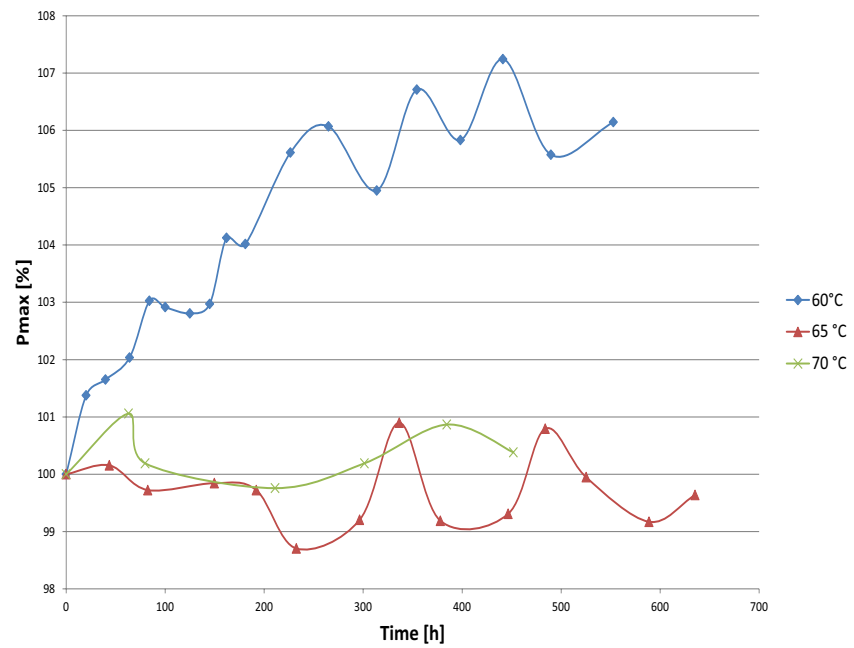

Fig. 5. Power curve normalized to its initial state at each annealing temperature of sample 3 .

Table 3. Power evolution for sample 3.

\begin{tabular}{ccccc}
\hline $\begin{array}{c}\text { Temp. } \\
{\left[{ }^{\circ} \mathrm{C}\right]}\end{array}$ & $\begin{array}{c}\text { Power } \\
{[\mathrm{W}]}\end{array}$ & $\begin{array}{c}\text { Power } \\
{[\%]}\end{array}$ & $2 \mathrm{Wp}=100 \%$ \\
\hline 25 & 1.82 & 100 & 91 & \\
60 & 1.93 & 106.3 & 96.5 & +6.3 \\
65 & 1.92 & 105.9 & 96.0 & -0.4 \\
70 & 1.93 & 106.2 & 96.5 & +0.3 \\
\hline
\end{tabular}

the annealing procedure was finished, a subsequent pre-treatment cycle was again carried out. All IV characterizations were measured at STC (standard test conditions). The obtained results were compared with the evolution characteristics found for the degraded (i.e. initial) state. Figure 6 shows the evolution of module power at STC during the pre-treatment cycle for the degraded state (Fig. 6a) and the annealed state (Fig. 6b). In Figures $6 \mathrm{a}$ and $6 \mathrm{~b}$ the power was normalized to the initial

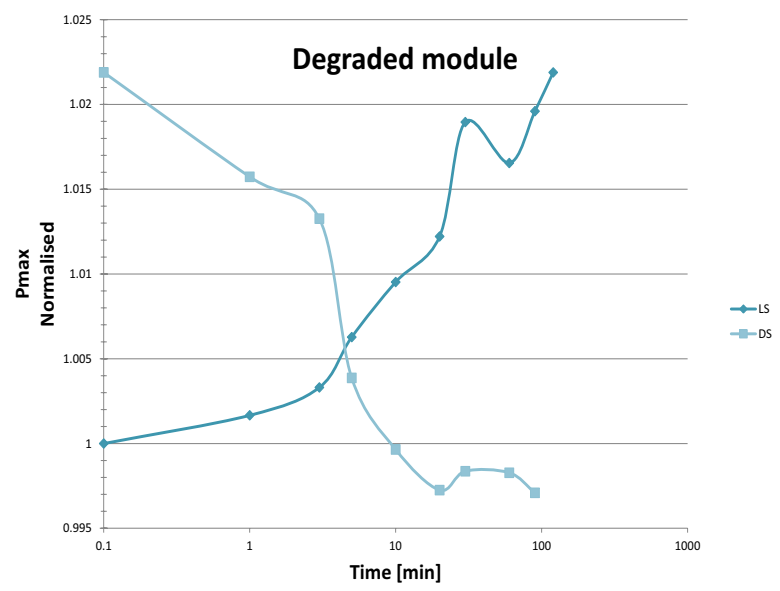

(a)

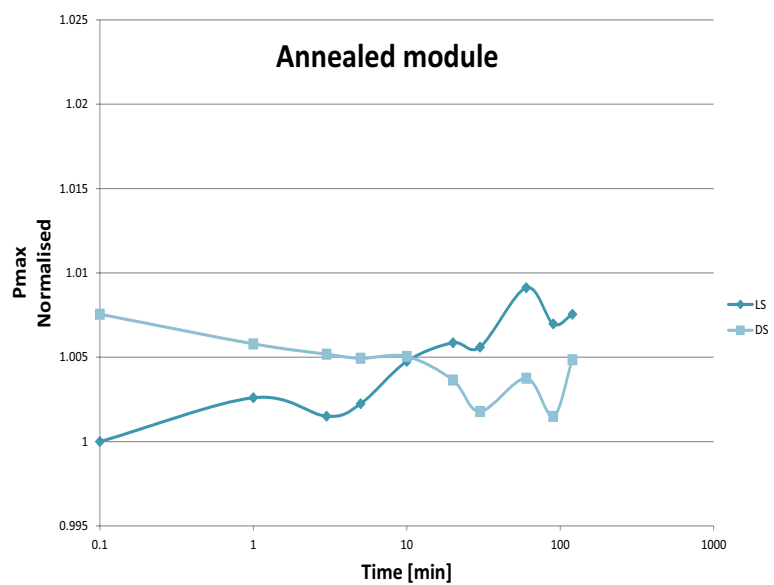

(b)

Fig. 6. Evolution of the normalized power of a double junction a-Si module (sample 2) before (a) and after (b) annealing.

measurement point of LS i.e. the IV curve of the module stored in dark overnight.

The last point $(t=120)$ of LS curve is the starting point $(t=0)$ of DS cycle and the end point of the DS cycle shows the completion of pre-treatment. The power change from the initial point of LS was compared with the final point of DS.

During the pre-treatment of the degraded module the output power, as shown in Figure 6a, gradually increases by $+2.2 \%$ under illumination (LS) followed by a relaxation with reversed dynamics while holding in dark (DS). The initial power of the degraded module was recovered after $10 \mathrm{~min}$ in the dark while the module power saturation $(-2.5 \%)$ was reached after $20 \mathrm{~min}$ at a value being slightly below the initial value before start of the LS cycle. Application of the pre-treatment procedure on annealed modules yields a remarkable change of the amplitude and dynamics of the metastable behavior. There, the magnitude of the power change due to illumination was much smaller during the period of the LS $(>0.8 \%)$ and DS $(<0.3 \%)$ treatments, respectively (see Fig. 6b). 


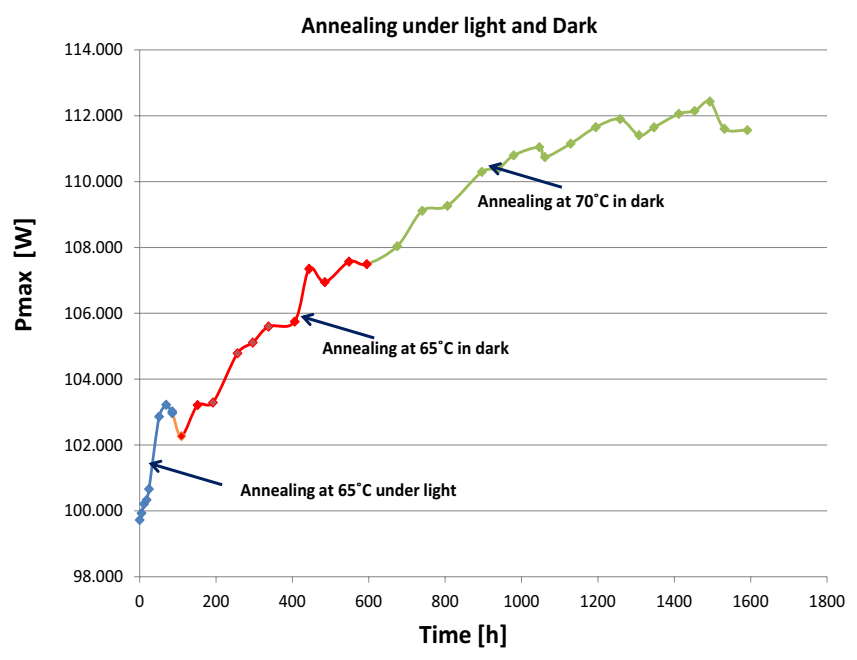

Fig. 7. Annealing curve of sample 2, low temperature annealing with light and without light.

Table 4. Power evolution for sample 2.

\begin{tabular}{ccclc}
\hline $\begin{array}{c}\text { Temp. } \\
{\left[{ }^{\circ} \mathrm{C}\right]}\end{array}$ & $\begin{array}{c}\text { Power } \\
{[\mathrm{W}]}\end{array}$ & $\begin{array}{c}\text { Power } \\
{[\%]}\end{array}$ & \multicolumn{2}{l}{$118 \mathrm{Wp}=100 \%$} \\
\hline 25 & 99.726 & 100 & 84.5 & \\
65 & 102.97 & 103.3 & 87.3 & +2.8 \\
65 & 107.491 & 107.8 & 91.1 & +3.8 \\
70 & 111.562 & 111.9 & 94.8 & +3.7 \\
\hline
\end{tabular}

\subsubsection{Annealing under illumination}

A single module was used to follow a different annealing/illumination path. Sample 2 was used in order to analyze the correlation between illumination and annealing in combination, compared to the dark annealed modules (see Fig. 7).

During annealing in light at $65{ }^{\circ} \mathrm{C}$ and an irradiance of approx. $830 \mathrm{~W} / \mathrm{m}^{2}$ a stabilised power of $102.97 \mathrm{Wp}$ with an absolute increase of $3.2 \mathrm{~W}$ after $85 \mathrm{~h}$ were obtained. According to the graph, the portion of annealed power with light was considered stable from the final three consecutive measurement points, in degree of their deviation in power of $\pm 0.1 \mathrm{~W}$. Following this, annealing in dark for around $509 \mathrm{~h}$ at $65^{\circ} \mathrm{C}$, lead to a further increase to $107.4 \mathrm{Wp}$ with a $\Delta P$ of $5.2 \mathrm{~W}$. The power increase from $65{ }^{\circ} \mathrm{C}$ to $70^{\circ} \mathrm{C}$ was $112 \mathrm{Wp}$ with an increase in $4.6 \mathrm{~W}$ and overall increase in power after the final annealing step was $112 \mathrm{Wp}(12 \%)$ from its degraded state of $99.7 \mathrm{Wp}$.

All results for the measured power values stayed stable at room temperature i.e. the module state did not change even after storing the modules in dark for some hours and the IV characterization gave reproducible results.

\subsection{Discussion}

\subsubsection{Annealing}

The results of the annealing cycles show that a huge part of the initial (manufactured) power can be recovered by annealing in the dark even at low temperatures. This is interesting for two reasons. First it is definitely below the temperature damaging the module structure. Second it is at temperatures measured as operation temperatures in the field. As it has been observed as a seasonal effect seen in building integrated a-Si technologies, where the power of the PV modules improves during summer and decreases during winter season [21]. Therefore, it was interesting to use outdoor operating temperatures of PV modules in dark to observe the effect of low temperature on the recovery of power. The annealing was done for a-Si double junction technologies, glass-encapsulated and fully plastic encapsulated modules.

Interestingly, the series resistance was reduced and the shunt resistance was raised, after each annealing cycle. The change in shunt resistance represents the recombination losses in the bulk. This causes reduction in the fill factor. Through annealing a change in shunt resistance also improved the fill factor, for example in sample 1, the fill factor was increased from $63.4 \%$ to $68.9 \%$. This shows a reduction in the recombination losses through low temperature annealing. Also, with each pre-treatment the modules showed a decrease in metastabilities. This also suggests that there is some kind of stabilization introduced in the structure of the a-Si technology.

Finally, presented measurement also shows how to differentiate between the spectral and thermal annealing effects as a-Si technologies as shown in Figure 7, where the difference between annealing in light and annealing in dark can be seen, where it exhibit a power recovery dependence on the incident spectrum [22].

Retain in power also suggests that some change in metastabilities is occurring inside the a-Si:H technology. The overall change was almost the full module degraded power from the manufactured state.

\subsubsection{Arrhenius behavior}

The annealing procedure was done for a long duration of time - around $2000 \mathrm{~h}$, but our purpose was to investigate the main evolution of power correlated to defect annihilation. The energy barriers of the metastable state from the ground state as found in literature have a variation from $0.9 \mathrm{eV}$ to $1.3 \mathrm{eV}[12,23]$.

Since defect annealing is a thermal activated process, it must show an Arrhenius behavior. The stabilized power at each temperature was plotted vs. (1000/temperature) for sample 1. It follows a perfect Arrhenius curve, as shown in Figure 8.

Annealing might have changed some important parameter in the a-Si:H structure, this could be the $\mathrm{Si}-\mathrm{H}_{2}$ which is according to the experimental research suggesting its increase from $50{ }^{\circ} \mathrm{C}[24]$. The di-hydride bonds require much less activation energy than the single $\mathrm{Si}-\mathrm{H}$ bonds. This is also proven by these researchers from [24]. This might be an essential factor in increasing the efficiency of the module. Also, as the $\mathrm{Si}_{-} \mathrm{H}_{2}$ lies generally in the shallow traps, this suggests that it requires low activation to transport in the material. 


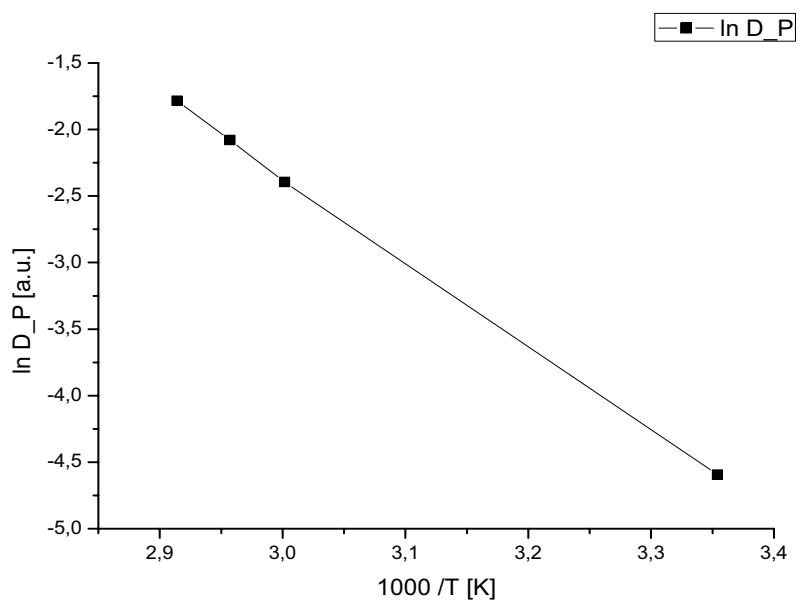

Fig. 8. Shows the Arrhenius curve for sample 1, the annealed power showing the correlation to the defect densities.

Nevertheless, from the graph in Figure 8, no activation energies could be extracted as described in Section 2.2. Although it is just an assumption we think that the power changes which were measured in the presented experiments may origin from defect states with similar activation energies. Some of the modules were able to reach their initial state (quoted by the manufacturer) of power even after getting degraded below their nominal power. Recover of power to its initial state refers to change in the metastable behavior.

Therefore, there might be majority of metastable defects in a-Si:H caused by low energy defects rather than higher activation energy. A detail study at the cell level must be carried out to allow deciding these questions, which cannot be solved on the module level. This will lead to naming the potential candidates for the changes in photoconductivity, as discussed here.

Finally it should be mentioned that, in field degradation is happening at the high irradiance and at around temperature of around 60 to $70{ }^{\circ} \mathrm{C}$. Therefore, in outdoor conditions always the case of annealing like shown in Figure 7 for sample 2 (for the part- annealing at $65{ }^{\circ} \mathrm{C}$ in light) will be valid.

There are still many open questions from the low temperature annealing since no measurements could be performed at the material level. Optical characterization technique, electroluminescence imaging, did not show any changes in the treated modules, when compared with its initial degraded state to the fully annealed state. This says something about no damages and changes being done externally but in the internal structure of the module.

\section{Conclusion}

Low temperature annealing caused several changes in the modules behavior: (a) an increase of power was recorded for all annealed modules power, (b) the short term metastable behavior was decreased while the overall power rose and (c) the difference between annealing under illumination and in the dark was shown. For the underlying driving process the thermal nature could be shown as the results follow Arrhenius behavior. This observation suggests, that the presence and the dynamics of metastabilities in double-juncion a-Si:H modules are related to optically/thermally induced changes of the intrinsic defect density.

The almost full power recovery and activation energy suggests that the defects which cause degradation might be just of low activation energy. This findings and conclusions were all done on module level, which lowers their value for reason of model character. Nevertheless, we hope, that these kind of experiments can also help to understand full scale mass marked modules in their behavior much better.

\section{References}

1. Q.Y. Research, Market Research Report on Global and China Amorphous Silicon Thin Film Solar Cell Industry, June, 2014

2. European Commission, Communication from the commission to the European parliament and the council Renewable Energy: Progressing towards the 2020 target, 2011

3. D. Craciun et al., in Proceedings of 27th PVSEC, Frankfurt, 24-28 September, 2012, pp. 3074-3081

4. J. Wagner et al., in Proceedings of the 26th European PVSEC and Exhibition, Poster, Hamburg, 5-9. September, 2011

5. S. Krauter, A. Priess, in Proceedings of 25th PVSEC, Valencia, 6-10 September, 2011, p. 3141

6. V. Helmbrecht et al., in Photovoltaics International 15th Edition, April 2012, pp. 194-201

7. J.A. del Cueto, B. von Roedern, Prog. Photovolt.: Res. Appl. 7, 101 (1999)

8. R. Ruther et al., in 33rd IEEE Photovoltaic Specialists Conference, 2008, PVSEC 08 (2008), pp. 1-5

9. M. Rennhofer et al., Correlation of weather and spectral changes for evaluation of thin-film PV module performance, in Proceedings of the "Thin Film Conference", München, 2011, pp. 56-62

10. L. Staebler, C.R. Wronski, Appl. Phys. Lett. 31, 292 (1977)

11. M. Stutzmann, in Amorphous and Microcrystalline Semiconductor Devices, edited by J. Kanicki (Artech House, Boston, 1992), Vol. II, p. 129

12. M. Stutzmann, W.B. Jackson, C.C. Tsai, Phys. Rev. 32, $23(1985)$

13. H. Branz, Solid State Commun. 105, 387 (1998)

14. S. Zafar, E.A. Schiff, Phys. Rev. B 40, 5235 (1989)

15. IEC 60904-1 Ed.2.b, photovoltaic devices - part 1, measurement of photovoltaic current-voltage characteristics, 2010

16. IEC 60891 Ed. 2, Procedures for temperature and irradiance corrections to measured I-V characteristics of photovoltaic devices, 2008

17. IEC 61646 Ed. 2.0, Thin-film terrestrial photovoltaic (PV) modules - Design qualification and type approval, 2008 
18. A. Dangel, Staebler Wronski effect in Photovoltaic modules, Master thesis, FH Technikum, Wien, 2014

19. S. Novalin, M. Rennhofer, J. Summhammer, Thin Solid Films 535, 261 (2013)

20. A. Mittal, Short-term metastable effect in a-Si technology, Master thesis, Austrian Institute of Technology, 2012
21. A. Virtuani, L. Fanni, Prog. Photovolt.: Res. Appl. 22, $208(2012)$

22. Y. Hirata, T. Tani, Solar Energy 55, 463 (1995)

23. A. Kolodzeij, Opto-electronics Review 12, 21 (2004)

24. P.K. Lim et al., J. Phys.: Conf. Ser. 61, 708 (2007)

Cite this article as: Ankit Mittal, Marcus Rennhofer, Angelika Dangel, Bogdan Duman, Victor Schlosser, Power change in amorphous silicon technology by low temperature annealing, EPJ Photovoltaics 6, 65304 (2015). 